\begin{tabular}{l|l} 
Variants & $\begin{array}{l}\text { Variants } \\
\text { The Journal of the European Society for Textual } \\
\text { Scholarship }\end{array}$
\end{tabular}

$14 \mid 2019$

Varia

\title{
The Archival Impulse and the Editorial Impulse
}

\section{Paul Eggert}

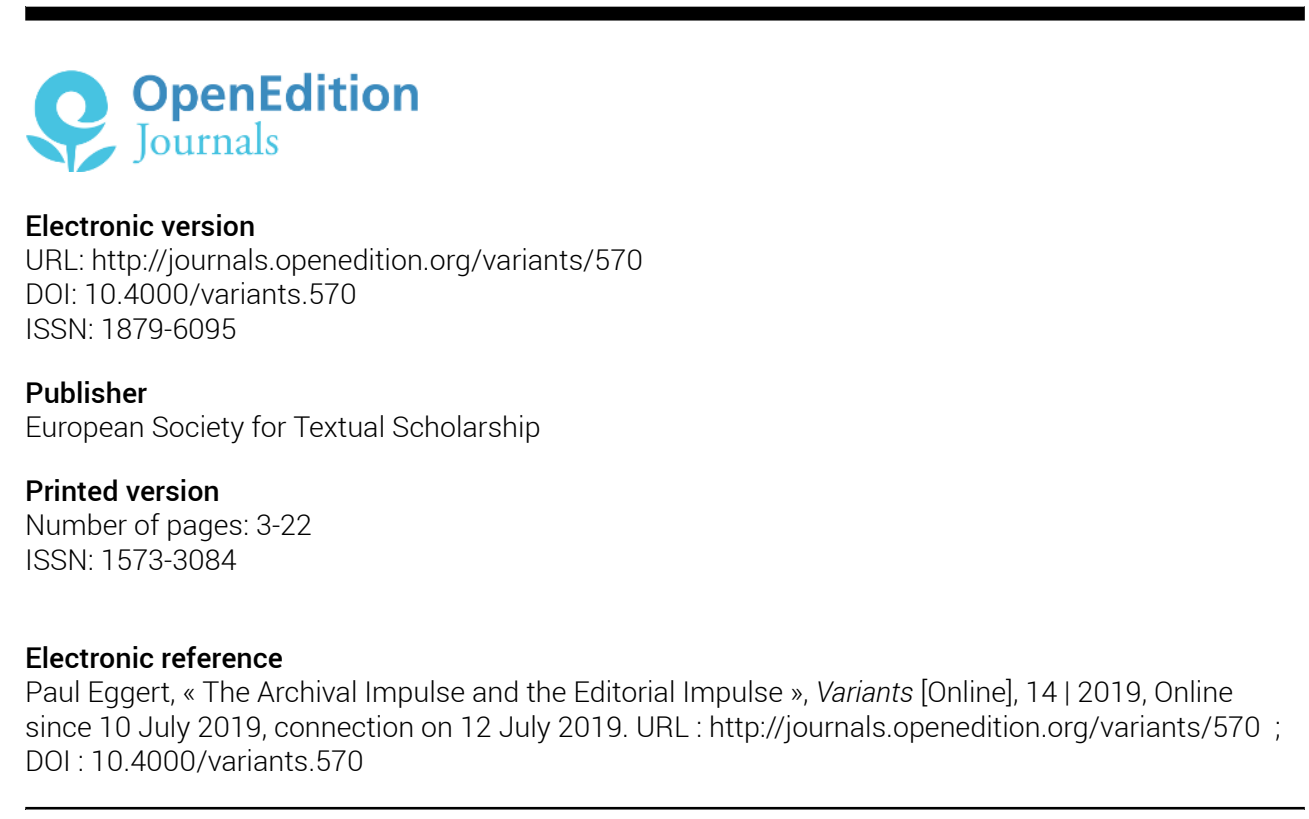

The authors 


\title{
The Archival Impulse and the Editorial Impulse
}

\author{
Paul Eggert
}

\begin{abstract}
There is no firm, outside vantage-point from which to survey and thus to define archive and edition as securely differentiated categories. As readers we inhabit the same textual field as the approaches to documents and texts that we seek to define. To record is first to read and analyse sufficiently for the archival purpose; to interpret is first to read and to analyse sufficiently for the editorial purpose. In practice, the archival impulse anticipates the editorial, and the editorial rests on the archival. We may envisage the relationship of archive and edition as a horizontal slider or scroll bar running from archive on the left to edition on the right. In this model every position on the slider involves interpretative judgement appropriate to its purpose. Every position along the slider involves a report on the documents, but the archival impulse is more document-facing and the editorial is, relatively speaking, more audience-facing. Yet each activity, if it be a scholarly one, depends upon or anticipates the need for its complementary or co-dependent Other. The archival impulse aims to satisfy the shared need for a reliable record of the documentary evidence; the editorial impulse to further interpret it, with the aim of orienting it towards known or envisaged audiences and by taking their anticipated needs into account. The sliding scroll-bar model dispenses with recently expressed anxiety about digital literary archives (special-purpose collections) replacing editions. The latter will continue to be prepared as long as there are readers whose requirements need to be served. The slider model helps us to survey the full range of archival and editorial possibilities. The term "representation" embraces the archival impulse. The editor's aim, on the other hand, is less to represent something that is pre-existing than to present something (the text of a version, the text of a work, a process of writing) that typically has not existed in precisely this form before, together with the critically analysed materials necessary to defend the presentation.
\end{abstract}

IN TEXT-CRITICAL CIRCLES the term "archive" is increasingly used to mean a special-purpose collection of analog or digital surrogates of original text-bearing materials that centre on a particular subject, author, work or group of works. ${ }^{1}$ This meaning of "archive" departs from the professional archivist's stricter and principles-based definition. ${ }^{2}$ But that departure need not detain us long in view

1 This is a revised version of a paper given at the 2016 annual conference of the European Society for Textual Scholarship in Antwerp.

2 Three principles underlie the professional archival pursuit: archives are organized according to provenance not, say, by author; materials are "managed as aggregates, not as collections of individual items"; and "the original order imposed by the source" of the materials ("records") is "preserved or recreated if it is known" (Theimer 2012).

For a brief account of the looser definition (which Theimer terms "digital collections"), see the "keyword" Archive defined by Coats and Dean (n.d.). See also Bode and Osborne 2014; and Manoff 2005. Note that the "archival divide" that is said now to separate archivists and historians shows that the looser definition depends on an out-of-date 
of the wide currency our looser metaphorical definition has clearly attained - attained, that is, on account of its usefulness. One thinks of the Rossetti Archive, the Walt Whitman Archive, the Samuel Beckett Digital Manuscript Project whose worldwide web address is, revealingly, beckettarchive.org. A 1990s habit of naming has become normalized. The ensuing neglect of the distinction between "archive" and "edition", which various people have raised recently, is my subject here. ${ }^{3}$

\section{I}

Some scholars in the textual studies community have seen the need for the distinction between archive and edition as they design their projects. It seems, for instance, to map nicely onto the dual Text Encoding Initiative (TEI) schemas for documentary features on the one hand and textual on the other being used for some projects now. ${ }^{4}$ But equally, it is clear that some people bristle at the very proposal of a distinction between archive and edition since it implies to them that transcription is mere grunt work whereas text-establishment and commentary are the preserve of an editorial elite. They rightly point out that transcription of manuscripts involves judgement, often expert judgement, not just in the act of reading the manuscript text and its sometimes nearly indecipherable layers of correction and revision but also in the considered choice of TEI codes in which to capture the information (TEI 2007).

However, in an article written in 2012 and published the following year Peter

assumption among historians about the nature of archives and the "scientific evidence" offered by their records: see further, Blouin and Rosenberg 2011.

The new self-consciousness amongst archivists and historians sparked by the writings of Michel Foucault and Jacques Derrida (especially the latter's Archive Fever: A Freudian Impression) asks, among other things, "Who actually should determine what the archives retain, and by what criteria?" (Blouin and Rosenberg 2011,9). This kind of question reflects Derrida's intervention and the consequent creation of a new humanities consensus, outside the world of professional archivists, that (1) no archive is complete; that (2) every document is partial so that the reason for its collection needs to be understood and, equally, its contents need to respond to an organizing narrative if it is to be made to yield its testimony (so that part of its meaning always resides in the interests brought to the investigation); and finally (3) that digital literary archives have a bias towards the canon. See further, Yale 2015, especially 332-3.

This line of questioning remains applicable for special-purpose collections. In due course, the pragmatic agreement amongst textual scholars on what to include and, more generally, what special-purpose literary archives are will be sceptically inspected. Nevertheless the slow process of moving towards agreement over the last decade or two gives reason to assume that it will remain robust for some time to come.

3 E.g. Shillingsburg 2014; Van Hulle and Nixon, 2015: “The Beckett Digital Manuscript Project functions both as a digital archive and as a genetic edition".

4 E.g. the digital FaustEdition (Bohnenkamp, Henke and Jannidis 2016) and the Canterbury Tales project (Robinson and Bordalejo n.d.) use dual TEI schemas, even though the resulting displays are very different (genetic on the one hand, stemmatic on the other). 
Robinson observed that the predominant effort amongst digital textual scholars was going into document transcription and coding, with the transcription often being assumed to be, or being portrayed as the same thing as, an edition (Robinson 2013a). By 2013 he was concerned that the tendency of the digital medium to privilege the document as the object of attention over the work, and the devotion of so many scholars and programmers to that documentary goal, presaged the effective end of scholarly editing as we have known it (Robinson 2013b).

The appearance of Elena Pierazzo's book Digital Scholarly Editing two years later doubtless substantiated his fears. She details the recent flowering of digital editions of individual modern manuscripts treated as documents and she questions the special standing of critical editing of multi-witness works as such. All involve interpretative judgement, she observes, and goes on: "if it is enough to add a [collation] tool to one's archive to transform a documentary edition into a critical edition [. . .] then the distinction between the two forms of scholarship seems rather unsubstantial." But having entertained that idea she backtracks. The very next sentence says: "It is not the tool that makes the difference, obviously, but this example underlines how the two endeavours are based on very similar scholarship" (Pierazzo 2015, 197). ${ }^{5}$

The recent flourishing of digital documentary editions is probably, as Pierazzo implies, a reflection of the development of a technology: TEI. But surely we need to resist a theory of digital editions that is determined and limited by a specific technology. A keener understanding of what, at the moment, is frustrating the development of the traditionally more ambitious editions of multi-witness works is needed. In addition, we need to be able to differentiate between digital forms of the documentary-diplomatic edition and the critical edition in a way that does justice to both.

There was another dimension to Peter Robinson's lament in 2013. In an introductory paper to the editorial conference called Social, Digital, Scholarly Editing that he convened at the University of Saskatchewan in July 2013 he explained the stalling of multi-witness digital editions as a problem of editors having become dependent on digital-humanist programmers (Robinson 2013c). The dependency arose from the need of editors for tools to process the customized set of TEI codes that projects had found it convenient to use in their transcriptions. The case was similar to the building of customized interfaces that, inevitably, cannot be sustained long into the future. "It is time to assert

5 The claim about the collation tool is sourced to Van Hulle and Nixon 2013; the 2015 revision contains the same wording: "Usually, digital 'archives' are distinguished from 'editions' because the latter offer a critical apparatus. An interoperable tool such as CollateX can enable any user - not necessarily an editor - to transform a digital archive into an electronic edition". This may be true of genetic archival projects, which exist principally to facilitate study of the compositional process rather than to provide emended reading texts of works or of versions. But it is not true of critical editions nor of those documentary editions that employ emendation for the reader's convenience. A line is crossed at that point. See further, below; Sahle 2007, 2008; and Pierazzo 2011. 
the value of editions in the digital age", Robinson resonantly declared, adding provocatively: "Digital humanists should get out of textual scholarship: and if they will not, textual scholars should throw them out" (Robinson 2013c, 2). Put less provocatively, what he meant was that a standard set of tools and a workflow environment need to be created so that editors can get on with what they know best: edition-making. When Robinson's paper appeared almost immediately in a blog post it got emotions running high at the international 2013 Digital Humanities conference at Lincoln, Nebraska only a week later.

I have answered the Robinson of 2012, and elsewhere I have tried to demonstrate the unkillable robustness of the work concept both for editors and for literary studies. ${ }^{6}$ In the present essay I address the question of nomenclature that keeps bubbling to the surface in the recent debate without being satisfactorily resolved. The question is: What, in the digital arena, is an archive and what is an edition? And, how should this affect our characterization of the types of editorial project that we may otherwise be tempted to run together.

I was at the same Saskatchewan conference in July 2013. My paper (Eggert 2016) was about understanding the scholarly edition as embodied argument about the work instead of, as is traditional, seeing the edition only as a presentation or representation of the work. ${ }^{7}$ Mine, granted, is a counter-intuitive proposition. I have been putting it forward for some years now, as have others, with different emphases, including Erick Keleman $(2009,73)$ and, most notably and thoughtfully, Hans Walter Gabler (2010). ${ }^{8}$ Robinson and Peter Shillingsburg also took it up in their conference papers at Saskatchewan. ${ }^{9}$

In characterizing the edition as argument I had merely articulated what every editor of multi-witness works learns the hard way: that the editing involves a complex series of linked judgements, each of which tests the others so far

6 Eggert 2013; and, for the viability of the work concept, Eggert 2012b. Robinson writes: "a scholarly edition must, so far as it can, illuminate both aspects of the text, text-as-work and text-as-document. Traditional print editions have focussed more on the first". Whereas it was hoped that digital editions "might redress this balance", he argues that the currently dominant view of digital editions, being document-centred, dissolves the work concept altogether $(2013 a, 123)$.

7 To which presentation or representation might be added "scholarly introductions, annotations, and textual histories": this is how Kenneth M. Price describes the value-adding contents of a scholarly edition that, together with the reading text, provide "editorial supervision and intervention in the reader's experience of the text" (Price 2009 , $\S 27$ and see $\S 4$ ). The additive principle adduced by Price is the inverse of the edition-as-integrated-argument principle that I was proposing.

8 The development of the edition-as-argument idea from the late 1980s is detailed in Eggert 2016, 809. The quotation from Kane and Donaldson on which Keleman relies (scientific hypotheses are liable to "replacement" upon "the emergence of new data") ignores, however, the role of a readership in reception. For a reply to Gabler's idea of the edition as a set of discourses in dynamic argument with one another, see Eggert 2013.

9 Though not always in the nuanced way that I believe is necessary. See Robinson: "An edition is an argument about a text. We need arguments; without arguments, our archives are inert bags of words and images" (2013c, 1). 
reached. But the implications of the proposition only grew clearer to me as my involvement with digital scholarly editing in the early 2000s forced me to think about the landscape of actions, responsibilities and meanings that the changed medium brought with it. One principal implication emerged. If the edition is to be seen as an argument then it is necessarily one that is addressed to an audience in respect of the documents gathered and analysed for the editorial project, usually documents deemed to witness the textual transmission. If the edition is an argument addressed to an audience then it must anticipate the needs of its readership. This view of things places the editor in a medial or Janus-faced position, looking in one direction towards the relevant documents and looking towards the audience in the other.

So to edit is to mediate, to come between. ${ }^{10}$ Documents are not self-declaring and may contain all kinds of impediments to their consumption. But since the need for making sense of the documentary condition of texts will never disappear, especially when multiple witnesses are competing for our attention, I suspect that Robinson's anxiety about what is happening to editorial activity in the digital medium is premature and that deficiencies of current tools that currently stand in the way will eventually be overcome. Robinson is right that we lack a standardized set of tools that an editor can simply pick up and use. The digital scholarly edition has not yet settled into a widely subscribed format. But when it does, when we understand the logic of its digital environment better, the range of responsibilities of the editor will likely be different than they were in print. Even so, the fundamental necessity of mediation will remain.

This defining editorial act will typically be embodied in a reading text and in the ancillary matter that surrounds and justifies it. The editorial mode and its display will be limited only by the editor's ingenuity and the available tools. The result will be judged by readers able to assess the explicit or implicit argument that the edition embodies. Thus editions will be identifiable as such by the cogency and rigour of their analysis of the archival data, which, in the force-field of the edition, is converted into evidence in the service of the editorial argument.

\section{II}

These introductory remarks set the stage for a discussion of the disputed distinction between archive and edition. Some people believe the distinction ought to be a firm one. Brüning, Henzel and Pravida (2013), for instance, three scholars associated with the FaustEdition, understand the distinction between archive and edition in terms of Hans Zeller's famous distinction of 1971 between Befund and Deutung (record and meaning, see Zeller 1995). Although I too have been attracted to the parallel I now feel that applying Zeller's theory in this way is a mistake. Unfortunately the two categories - record and interpretation cannot gain the firmly differentiated objective footing for which philologists

10 I have been drawing attention to this obvious, if nevertheless often overlooked, fact since the mid-1990s: see Eggert with McCauley 1995. 
have traditionally yearned. This is because humanly-agented reading is intrinsic to both of them. There is no firm, outside vantage-point from which to survey and thus to define archive and edition as securely differentiated categories. As readers we inhabit the same textual field as the approaches to documents and texts that we seek to define. ${ }^{11}$ To record is first to read and analyse sufficiently for the archival purpose; to interpret is first to read and to analyse sufficiently for the editorial purpose. In practice, the archival impulse anticipates the editorial, and the editorial rests on the archival. They are not separate categories and certainly not objective or transcendental ones. As co-dependents they are perhaps best understood as being in a negative dialectical relationship with one another, that is, each requiring the other to exist at all, yet each requiring the other's different identity to secure its own.

So, how better may we envisage the relationship of archive and edition? I propose that we think of a horizontal slider or scroll bar running from archive at the left to edition at the right. In this model every position on the slider involves interpretative judgement appropriate to its purpose. All stakeholders will want to position themselves at one place rather than another along that slider, or at one place rather than another depending on what responsibilities they are discharging at any one time. To see things like this is to want to recast the archive idea as archival impulse and its complementary opposite as the editorial impulse. Based on impulse or tendency, the distinction that I am proposing is pragmatic rather than ideal. To the extent that the archive-edition distinction is deployed it has to be understood, then, as a shorthand standing in for what is in fact a more nuanced reality. I wish now to consider where this approach leads us. ${ }^{12}$

Every position along the slider involves a report on the documents, but the archival impulse is more document-facing and the editorial is, relatively speaking, more audience-facing. Yet each activity, if it be a truly scholarly one, depends upon or anticipates the need for its complementary or co-dependent Other. The archival impulse aims to satisfy the shared need for a reliable record of the documentary evidence; the editorial impulse to further interpret it, with the aim of orienting it towards known or envisaged audiences and by taking their anticipated needs into account. Another way of putting this is to say that every

11 I am grateful to Jerome McGann who has influenced me here (see, e.g., McGann 2014, 197-8).

12 I first proposed the qualified terms "archival impulse" vs "editorial impulse" (rather than the starker "archive" vs "edition") in Eggert 2012a. The distinction made its way into my presidential address to the Society for Textual Scholarship in March 2013 (Eggert 2012b, issued August 2013), and made a cameo appearance in a paper of 2013 published as Eggert 2016. Via oral transmission and warmly acknowledged, the "impulse" idea first made its way into these pages in an article by Peter Shillingsburg, the generosity of whose thinking has benefitted mine in ways too numerous to specify for over three decades now, including over issues where we have disagreed $(2014,20)$.

The slider metaphor is a natural extension of the terms spectrum or continuum, both of which I use in Eggert 2009 and which Elena Pierazzo picks up (2015); see also her Figure 
expression of the archival impulse is to some extent editorial, and that every expression of the editorial impulse is to some extent archival. Their difference lies in the fact that they situate themselves at different positions on the slider.

The question may be asked: Why is it necessary to make this distinction, now, after centuries of editorial effort have got by without it? In print, after all, we just prepared editions: critical, historical-critical, documentary-diplomatic or, more recently, genetic editions. To the extent that there was a distinction between archive and edition it was subsumed within other, louder disputes over the valuation of types of edition. Fredson Bowers and G. Thomas Tanselle used to insist on the difference between critical and non-critical scholarly editions. According to them, parallel-text editions, type-facsimile editions, documentary editions presenting transcriptions of facsimiles, and variorum editions were not critical editions since no reading text was editorially established or preferred. ${ }^{13}$

2.5, which portrays different kinds of edition on a line between works and documents (p. 52). Drawing on Patrick Sahle's characterization of types of digital edition (Sahle 2008), she comments:

The shift between archives, libraries and editions is subtle and happens along a continuous line where minimum and maximum scholarly engagements are distributed. The difference between these resources is therefore quantitative: the more scholarly argument [there is] the more likely there is to be an edition. However, the quantitative definition becomes also qualitative in the moment that scholarly engagement corresponds to an increased level of reliability, accuracy and, generally, quality of the editorial product. While the distinctions are blurred, they still hold from a scholarly point of view. Nevertheless, no reliable criteria, but the judgement of the scholar-user, are offered as a means for classifying digital scholarly editions as distinguished from other text vessels.

(Pierazzo 2015, 201)

The lack of "reliable criteria" is a problem for the modelling of editions that Pierazzo advocates. It is less so for the scholar-editors themselves.

Dirk Van Hulle comes close to my use: "the strict boundary between digital archives and electronic editions is becoming increasingly permeable, resulting in a continuum rather than a dichotomy" (Van Hulle and Nixon, 2013), as does Peter Robinson:

\footnotetext{
There should be an unbroken continuum, between the multiple resources created by libraries as they produce and put online more and more images of the manuscripts and books [. . .] through to the scholarly editions we might build within and on top of all these materials, where every word is scrutinized, every decision weighed, and where our aim is not just to record, not just to present, but to understand.
}

(Robinson 2013c, 4)

Perhaps Claus Huitfeldt has the most felicitous formulation: "As a first step, let us imagine representation and interpretation as points located at opposite ends of a continuum. Our task is to find somewhere along this continuum clear demarcation lines that allow us to decide, in particular cases and classes of cases, what is interpretation and what is representation" $(2006,195)$. See also Sahle 2007, 2008-, and 2016.

13 Each form was nevertheless seen as a scholarly edition. See Bowers 1966 and 1978 and Tanselle 1978. See also Eggert with McCauley 1995, which, on the basis of a survey of scholarly editions of literary works, and historical and other documents, as well 
German-style historical-critical editions were similarly, at least in Charlottesville where Bowers held court, only on the cusp of acceptance as being critical since the editorial effort was centred narrowly on decisions about the authorization of historical texts, with emendations limited to failures of the semiotic system that was said to constitute the particular historical text-version. It was plain to Anglo-American editors that their German counterparts' recording of the documentary history of textual transmission was more systematic and thorough than their own. Yet, in the establishment of reading texts, they were more conservative, less adventurous. But whichever perspective editors adopted when preparing a historical-critical apparatus, or an Anglo-American one in support of an editorially emended reading text, they assumed that their role necessarily included a compilation and presentation of the evidence of textual transmission in a well-designed apparatus. Every entry acted as a check on the editor's discursive account of the transmission elsewhere in the volume: garrulous apparatus entries indicated the account was probably wrong, economic ones that it was probably right.

The systematic recording was a shaped report that, for practical reasons, stood in for what we have since come to expect of the digital archive (minimally, facsimiles and transcriptions). If facsimiles were to be reproduced in the print environment, whether with or without transcriptions, they would require a volume or series of volumes of their own, in effect a separate project. ${ }^{14}$ What print scholarly editors like me failed to fully appreciate - because the digital medium had not yet prompted us to do so as we established our reading texts, wrote commentary on them and painstakingly prepared the textual apparatus - was that we were serving dual functions as editors and archive reporters combined. Our textual apparatuses substituted for the archive we could not reproduce.

We called the result an edition. It was an integral conceptual unit. The book format, its material logic as a book, silently but potently confirmed this. The ancillary material (including the archive report) was oriented around, complexly linked to, and intellectually supportive of, the reading text. The book was a single whole. Every part of it was completed to the same time-schedule. Every part of it was brought up to a standard of accuracy that pertained across the whole edition equally. In other words, the very form of the edition tended to shield us from the now-obvious fact that our responsibilities were both editorial and, in the special sense I have given it, archival as well. We had two roles but we conceived of them as one. The book form had naturalized this assumption

as a wide range of other editorial endeavours (e.g. the collection of children's chants from the playground), came to the conclusion that the distinction between scholarly and critical editions was a fragile one, and that all editions that took a conscious attitude towards the text being presented as a problem in itself deserved the label "critical". That left the secondary but, for some scholarly purposes, more important distinction of whether or not they were full-scale editions based on an identification and collation of the relevant textual witnesses.

14 E.g. the James Joyce Archive, the Shelley-Godwin Archive, the Cornell Yeats. 
for us in advance.

But then gradually, during the 1990s, the possibilities of the digital domain dawned on us. The first so-called electronic editions were mostly yearned-for figments of our imagination, projections rather than actually achieved things. Nevertheless it was clear from early on that these new textual beasts, in whatever form they would turn out to take, would not need to be brought to a uniform standard of completion and accuracy at publication. This was because, in the digital domain, they would always be open to correction, revision and extension. In prospect at least, electronic editions were soon growing monstrously large as we envisaged loading them with more and more, mainly archival responsibilities than the printed book could contain. We print editors yearned especially to see much more of the primary evidence on which we customarily reported shown in facsimile in the electronic edition. We had naturalized the book form, yes; but we were also foremost amongst humanities scholars in fretting under its constraints. We envisaged a better future. But I am not sure that we asked: for whom?

That future took longer to arrive than we thought it would. It also brought unexpected problems with it. Solutions to questions of preservation were proposed and the idea of collaborative interpretation of reusable resources was given a basis in text encoding. A great deal of effort went and continues to go into tuning, adjusting and extending the definitions of elements and attributes by what deserves to be called the TEI movement, now with its own Board, funding, special-interest working groups and journal. The TEI Guidelines are now up to Version 5; each version has been bigger and more complex than its predecessor. Regular workshops spread the word and induct novices into the mysteries of TEI encoding.

An almost equal amount of effort has had to go, editorial project by project, into creating bespoke tools and ad hoc solutions to process the encoded data. This is because the original hope that the creation of TEI standards would allow for interoperability of encoded data among projects, and thus lead to a widespread take-up by software manufacturers, has proved to be deeply problematic, even illusory. ${ }^{15}$ Little wonder that the sheer quantum of effort devoted to mainly technical matters has fed the anxiety about the end of editing of multi-witness

15 The original claim of interoperability may be found in Ide and Sperberg-McQueen 1998, 1.4: "If both the creators of textual scholarly materials and software developers utilize a common encoding format, the texts may be used with any software package". SperbergMcQueen's influential claim that SGML encodings were "software independent" is often sourced to his paper at the Modern Language Association conference in San Diego in 1994: "For scholarly editions, such longevity is essential. And that is why I say that the development and use of software-independent markup schemes like SGML and the TEI Guidelines will prove more important, in the long run, to the success of electronic scholarly editions [. . .] than any single piece of software can". The goal of interoperability grew out of this belief, a persuasive one in the early-mid 1990s when the problems of dependency on proprietary software had become acute.

Time and experience have undermined it: see Schmidt 2014. He cites the opinions of prominent TEI-associated scholars who concur, including Martin Mueller (2011), written 
works with which I began.

One thing is for sure: the situation has given the old understanding of our duties as editors a shake-up. What we need now, I am urging, is not so much a new taxonomy of editing and archiving, as a sliding scale of document and audience orientations of the kind I have suggested, one that can self-adjust as new approaches in the digital arena are projected and put into operation.

\section{III}

Entertaining the edition-as-argument idea on the one hand and the slider model on the other permits various clarifications to emerge about archival-editorial projects in the digital domain.

If one accepts the model for the purposes of argument then, on the very left of the slider where the archival impulse is dominant, there is, to be strict, no robust or settled work attribution yet available, nor for that matter a version concept, since, once again strictly speaking, all the archivist-transcriber has at first are documents. Several, tens, perhaps hundreds, even thousands will be in need of transcription for the project. For practical reasons transcribers may be asked to record what they see on the page. Manuscripts showing multiple levels of verbal alteration may then be captured and encoded as documentary texts. Determination of whether such a text captures a version at all (since it may be only a fragment), or whether the alterations indicate the presence of two or more versions within the same documentary text, the result of the author

in his capacity as chair of its board; and Syd Bauman (2011), originally co-editor with Lou Burnard of the TEI: P5 Guidelines 2007. Bauman concludes that "interoperability is the wrong goal for scholarly humanities text encoding". Schmidt's argument is that, while there can be interoperability (and thus generalized tools) at the XML level, it is much harder to achieve at the semantic level. Programs that only check syntax or allow XML editing regard every XML file as "interoperable" because they do not care what is inside individual tags, but only that they are well-formed and syntactically correct. However, such programs are rather limited, such as a searching tool (e.g. XQuery) or an XML parser (e.g. Xerces) or an XML editor (e.g. oXygen). By contrast, the value-added semantic information of TEI is one level above that, and uses XML as its medium of expression. The flexibility of TEI allows humanistic interpretations to be expressed through a customizable computer-language syntax, but in practice this freedom leads to strong variations in the resulting encodings: through the choice of which features to encode, which tags to use and how to encode them. Software built on such shifting foundations must be customized for each project and cannot therefore be generally reusable. Thus in practice the TEI encoding scheme is unable to achieve true and practical interoperability.

For recent statements sceptical of the prospects of interoperability as a goal, see: (1) Jannidis (2010), in particular: "Interoperability of Programs" (551-56); (2) Cummings (2013): "Being able to seamlessly integrate highly complex textual structures in interoperable methods without significant conditions or intermediary agents is a fantasy"; (3) Holmes (2015; Holmes is co-editor of Journal of the Text Encoding Initiative); and (4) the abstract for Tara Andrews's keynote address at the TEI 2016 conference (Andrews 2016). I thank Desmond Schmidt for advice in compiling this note. 
returning to the document at different points in time to revise, is a matter for editorial postulation and argument once the provisional record has been more or less settled. ${ }^{16}$ The decision may be affected by visible or inferrable evidence: allied patterns of revision, say, on other manuscripts in the same manuscript book. Conversely, two or more documentary texts may be editorially deemed to be the same version: for example, successive newspaper reprintings of a poem, each printed without variation from the first.

In practice of course, work-and-version concepts are typically drawn down in advance, whether from tradition, from the fact of preceding publication or following bibliographical or codicological analysis. But sometimes these supports are lacking and often they are incomplete. Nevertheless, the terms "work" and "version" are useful categories by which to organize the archival effort, to keep it within achievable bounds. Their use is a silent indication that the archival impulse already bends towards the later editorial one. Thus the two are linked, because they are in need of one another, even at this early stage. Nevertheless, the drawing-down has to be understood as always provisional because always open to editorial reinterpretation or challenge. In a complete poetry project, for instance, the status of transcribed documentary texts, especially in manuscript, will become clearer as a second-stage editorial attention is brought to bear. Variant titles and heavy revision may initially mask work-version relationships, and version status can remain arguable.

As the project subsequently proceeds, the document-facing transcription, now tentatively completed, begins to come into a dawning editionhood of its own as the scholar-transcriber draws the documentary details into a shaping editorial argument about their history and significance. Even if originally prepared for private uses, the transcription now bends that document's textual witness towards an envisaged readership. Any and every emendation that makes the text more legible or usable is done on behalf of a readership, and that fact shifts the project a few points along the slider to the right without having quite reached the midpoint. Nevertheless, the archival pull of the document, of fidelity to the document, remains strong. This is the first clarification.

Once the relevant transcriptions for a multi-witness work have been prepared and checked, once the archival impulse has been satisfied, a second clarification emerges from the slider model: automatic collation of those witnesses is the pivot between the archival impulse and the editorial impulse. ${ }^{17}$ It is the midpoint on the slider. The editor considers the meanings of the data produced by

16 Work and version attributions being editorial is a logical extension of the argument in Shillingsburg that the material forms that texts take need to be distinguished from texts themselves: "Drafts have the same ontological status as versions; they have no material existence. [. . .] A version is a coherent whole form of the work as conceived and executed by the author within a limited time in pursuit of a reasonably coherent or constant overall intention" $(1996,46)$.

17 Technical advances mean there is no longer any need to think of the collation as a strictly editorial responsibility as print editors used to do. Automatic collation tools and the algorithmic creation of stemmata are rapidly rendering that assumption outmoded. 
the collation and confirms, corrects or discards the provisional assignation of versionhood and workhood that had helped organize the archival effort.

I use these unfamiliar terms ("editionhood" too) to unsettle the apparently objective status that we habitually accord works and versions. The preceding scenario has just shown that they are not givens, not objective. Rather, these categorizations emerge. A well-mounted argument, reinforced by the results of collation, may convince that their designation as such provides a strongly pragmatic hypothesis that explains the available evidence and forms a basis upon which it is safe to proceed editorially. As this occurs the position on the slider begins to move to the right.

The editor finds it harder and harder to resist the pull of work or version concepts as containers for shaping the data into a legible form for readers. As the editorial impulse gains ascendancy — as archival data is converted into evidence in support of the editorial argument - a more fully reader-facing edition comes into focus. Documentary fidelity is by no means lost sight of - the slider model insists on it - but is now consigned to the archival expression of the project.

Although the slider links all interpretative archival-editorial decisions on the same continuous scale it is obvious that a transcriber's decision to record as unobjectionably as possible the tags and attributes for, say, italic rendering involves a different level of judgement than the system-wide decisions that an editor must make. The project workflow will wisely respect that reality. It will normally make sense to do the reader-oriented editing after the archival effort is provisionally finished. The archival phase will have generated all kinds of clues that will benefit the editorial effort, and the latter phase may lead to corrections and adjustments of the archive.

But what form should the digital edition take and how should it be stored, joined at the hip as it is to the archive from which it now seeks separation? Or, put another way, as it reaches towards the right-hand end of the slider - for a reader-facing editionhood? So far we know that such a digital edition will typically take the form of a reading text of the unit being edited (work or version) or the genetic development of the version or draft, supported by a commentary analysing the documentary evidence. The edition will be potentially only one considered application of that data, potentially only one of many, since there will usually be more than one possible argument about textual authority or authorization or, occasionally, about work-version divisions. Indeed, there will potentially be as many editions as there are organizing arguments. Each one, offered as an interpretation of the data in the archive, must then take its chances in the intellectual marketplace. It must persuade its readers or, in the case of a genetic edition, prove useful to those who study the genesis or emergence of text on the page under the hand of the writer. ${ }^{18}$

18 Hans Walter Gabler argues that the genetisch-kritische edition goes beyond the traditional formation of the genetic dossier (manuscript image plus transcription), traditionally prepared by the scholar to support genetic criticism (Gabler 2016). The edition brings topographic and time-based material considerations into the project, realized by 
I find support for my case in an article of 2016 by Patrick Sahle. For some years he has been compiling a catalogue of scholarly digital editions (Sahle 2008- ), so his thinking about his definitions (especially, for present purposes, the relationship of archive and edition) has been continuously refined as each contender for the catalogue was assessed.

He stresses the continuity of editorial traditions from the print medium to the digital and, by implication, the need for less special pleading about the changes in conception and execution (as opposed, say, to storage) that the digital medium has brought with it for scholarly editors: "Others may emphasise that our whole concept of editing is changing so completely that it may dissolve and be replaced by other labels. In my work, however, I see the continuity in the basic goals of providing reliable, trustworthy and useful representations of our textual and documentary heritage as the basis for further research in the humanities" (Sahle $2016,37)$. One of his criteria for whether a digital-textual project constitutes a scholarly digital edition is: "Does the edition suffice as a substitute for the previous editions or primary documents making it unnecessary to go back to them in most cases? Does it enable further scholarly research on a reliable and trustworthy basis?" (Sahle 2016, 38).

Such recognition of the functioning of editions as serving readers' needs - as reader-oriented - allows us to insert a lever of differentiation between archival and editorial efforts. It also wisely acknowledges that digitized facsimile images may, once equipped with suitable description, commentary and transcriptions, lead to the production of facsimile editions. But it also grants that the further establishment of reading texts of single- or multi-witness works, based on copytexts emended on argued grounds, was and remains another matter. On the slider, they would appear further to the right.

The sliding scroll-bar model dispenses with anxiety about archives replacing editions. Editions will continue to be prepared for as long as readers need them. Readers need reader-facing editions. ${ }^{19}$ The special-purpose collections that

markup correlated to the image. An argument about the genetic development is offered, embodied in markup aimed at text-fragments and perhaps additionally in external commentary pointing to the whole text. This strikes me as a sound defence of the claim that genetic "editions" are indeed editions.

However, Gabler claims an ontological foundation for genetic editions in arguing that the condition of the draft manuscript is, using Nelson Goodman's famous distinction, autographic (and therefore special to the materiality of the document) as opposed to the allographic condition of texts in transmission (e.g. printed texts). This claim ignores the fact that all texts share the same basic predicament (as D. F. McKenzie, amongst others, has shown). Reading materially embedded text is unavoidable whether it be in manuscript or printed form, even if the task of deciphering the evolution of text on a draft manuscript page can be very much more difficult than a printed counterpart of the final layer of that text. The examples Gabler offers to witness his ontology are not fully convincing. One is the double markup of the FaustEdition (Bohnenkamp, Henke and Jannidis 2016); but it is readily explicable as a function of TEI's intractable problem of overlapping hierarchies rather than a reflection of the ontology offered.

19 See Kenneth Price's observation: "the whole question of what is in keeping 
we call archives can be substantial achievements in themselves, and certainly they are indispensible to digital editing. But only a tiny number of readers will want or feel that they need face-to-face engagement with the original sources or will be able to make effective use of them. Expanding the constituency of such curious readers to help them engage with the primary documents is desirable, for a range of pedagogic reasons. But we have to be realistic about our chances of success. Accordingly, I believe we will continue to prepare editions in the digital domain if only because, on the slider, archival contributions are by definition document-facing. They have a responsibility to leave the textual difficulties encountered in situ for the next specialist user. Ordinary readers, on the other hand, will need those impediments to comprehension to have been editorially digested by commentary or emendation. ${ }^{20}$ As Horace put it in the Ars Poetica, "He takes the prize who mixes the useful with the pleasurable, giving the reader enjoyment and advice in equal measure". ${ }^{21}$

Because of the way in which it will likely be stored the digital edition will be better described as the editorial layer of the complete project. $^{22}$ It will be the normal point of entry for the reader. It will be up to the editor to link the

with the wishes of a writer is beside the point. We do not edit for writers themselves but for our own purposes as scholars and readers" (Price 2009, § 23). To serve readers by anticipating what they understand a work to be, editors draw down from the witness documents what they call textual authority. Often it is the authority of the author that is invoked. Confused commentators sometimes conflate this with textual ownership, which is entirely author-directed.

20 See Tim McLoughlin who argues that the language of electronic editions implies a user rather than the reader anticipated by print scholarly editions. "The text is now an 'archive', a 'resource"' $(2008,4)$. As the needs of worldwide users cannot be predicted he argues that annotation needs to become encyclopaedia-like, revealing the culture of which the text is an "archive". I prefer the term "index" and can foresee the advent of semiautomatic annotation through the compilation of shared N-grams from contemporaneous writings and via harvesting of proper nouns. More ambitious is the proposal of Scheirer, Forstall and Coffee 2016.

Nevertheless, as McLoughlin also argues, a bridging of the gap between users and readers is desirable via the design and architecture of the edition and constant reminders of and invitations to read the texts central to it. The user's needs will be addressed by what I am calling the archival impulse in the project and the reader's by the editorial. The user will treat the project as a digital work-site suitable for pursuing other endeavours; editions would be one of those endeavours. Finally, McLoughlin underestimates the extent to which printed scholarly editions have always had a reference-book function, with readers able to read with the grain in the traditional way he describes but also against the grain by consulting and finding versional multiplicity in the textual apparatus and using the annotation and commentary as arcs of further discovery.

21 Quoted by McLoughlin 2008, p. 3 n. 3. See Connor's extensive review-article of The Cambridge Edition of the Works of Ben Jonson Online (Connor 2015). Although he does not use the terms, the desirable balance between archival and editorial obligations is his considered theme.

22 Contrast this position with Hans Walter Gabler's description of the digital scholarly edition as "centripetal. It stores the comprehensive record of the material evidence of its research object at its own digital centre" (Gabler 2015). 
archival evidence to the editorial layer again and again, thus tempting the reader to go deeper. Provided that the project can be given a collaborative interface some readers may become enduring contributors to the project. This is the third clarification: apprehensions that single-document transcription projects are replacing work editions needlessly telescope the slider into a single disputed point. The slider model helps us to survey the full range of archival and editorial possibilities.

The fourth clarification is one of nomenclature: "representation" versus "presentation" as applied to the archival and editorial impulses. To establish the distinction I return to Sahle's essay. His definition of the scholarly digital edition is based on his prior definition of the scholarly edition per se: "A scholarly edition is the critical representation of historic documents" (Sahle 2016, 23). The term "critical representation" warrants inspection. ${ }^{23}$

Its benefit lies in the fact that it allows him to envisage archival and editorial endeavours as more or less continuous but without sacrificing any of the rigour associated with scholarly editing:

Criticism as a practice and a process may take different forms. Think of the rules that are applied in the transcription of a document. While the transcription itself is a representation, the specification of rules and their application make this a critical process. [. . .] [W] may take the word critical as a container for all those activities that apply scholarly knowledge and reasoning to the process of reproducing documents and transforming a document or text into an edition. The critical handling of the material is a second necessary condition for an edition. A representation without such treatment or the addition of information is not an edition but a facsimile, a reproduction or nowadays - a digital archive or library. Critical representation as a compound notion of editing aims at the reconstruction and reproduction of texts and as such addresses their material and visual dimension as well as their abstract and intentional dimension.

(Sahle 2016, 24-5)

The omnibus, inclusive term "critical" in relation to documentary texts seems at first a welcome one since it allows for a range of applications along the slider. But it does not afford a way of differentiating expressions of archival from editorial impulses such as I have been arguing is useful and clarifying.

More importantly, the term "representation" seems to apply rather better to the archival aim than it does to the editorial. "Representation" became a

23 "Document" is also more problematic than Sahle assumes. The main, traditional Anglo-American approach to critical editing did not see capturing the text of the document as the central aim but only as a subsidiary one. The text of the work (or, less often, a version of the work) was the typical goal. Documents were understood to be witnesses of texts that were always liable to contain unauthorized or accidental changes. The textual authority of documents was understood, therefore, to be mixed. The challenge was to rise above them in defensible ways. Sahle's definition bends towards the German historical-critical editorial tradition where the aim was to capture the text, whether in the reading text or apparatus, of all the authorized versions (usually the text of the authorized documents). Laudably, however, Sahle wishes his aim to be understood not as tendentious but as inclusive when he uses the term "document" (Sahle 2016, 23). 
ubiquitous term during the period of high theory of the 1980s and after. The so-called thing itself was felt to be inaccessible except via representations of it, usually discursive representations, and workings of power typically hung off that discursive condition. However, used more precisely in the present setting as Sahle does, "representation" does seem to apply aptly to the aim of transcribers of documents, especially in projects involving the encoding of the transcribed text. So the term embraces the archival impulse nicely.

But it does not satisfactorily describe the editorial impulse. The editor's aim is less to represent something that is pre-existing than to present something (the text of a version, the text of work, a process of writing) that typically has not existed in precisely this form before, together with the critically analysed materials necessary to defend the presentation. My distinction invokes the ordinary meaning of "a publication" as something that is presented (gifted, handed over) to a readership.

While an archival transcription is an attempt to capture the text of a historical document (representation), an edition claims to make present the text of the thing that has been subject to the editorial analysis (presentation). This distinction seems cleaner - there is less muddying of the waters - than trying to bridge, as Sahle does, the archival and editorial activities as both being forms of representation. ${ }^{24}$

Of course as Sahle points out, any one project, by virtue of its deep encoding, may be capable of algorithmically generating both representation and presentation. ${ }^{25}$ But that is only a technical matter - and, as already observed, our definitions should not be dependent on those technologies that happen to enjoy current popularity. The slider idea, on the other hand, captures the relationship of the archival and editorial impulses, linked at the hip yet forever pulling apart. And now we can place the representational and presentational goals on the slider too, in parallel with the archival and editorial. This placement will help us as we seek to name and thereby to understand our project outcomes. Nomenclature turns out to be no trivial matter.

There is yet a final clarification to report. Once the slider model is seen as accommodating expressions of both the archival and the editorial impulses, another constellation of interpretative activity looms into view even further to the right on the slider - or, it may be judged, so far to the right as to be off

24 The neo-platonic idealist might argue that the text of the version or the work once existed in the author's mind and so, to that extent, any edition of it is a representation. I have repeatedly shown that this idealist argument is flawed. See e.g. Eggert 2009, chap. 10.

25 According to Sahle, "deeply marked up textual code of the digital edition theoretically covers several views of the text and may lead to various presentations generated by specific algorithms" $(2016,27)$. Near the start of his essay he promises to come back to the difference between representation and presentation but in fact this statement is the only thing he has to say on the matter in this article. Elsewhere he distinguishes between data as representation and algorithmically generated media as presentation: see Sahle 2010. 
it entirely. Given the orientation of the edition towards reader-facing activity and away from the duties of transcription and collation now understood as archival, where should we locate literary criticism? Does it have a position on the slider? Traditionally, it has been excluded from printed scholarly editions on the grounds of its lack of objectivity and its relatively short shelf-life compared to the editing itself.

I cannot see why, in the digital domain, this exclusion should be mandatory. To be sure, textual commentary will remain a central part of the edition's argument. But need it, together with the factual explanatory notes, glossaries and maps be the only acceptable forms of commentary? Would not literary criticism, collaboratively contributed - date-stamped, signed, formally published and archived by the project - only benefit by its keeping company with the archival evidence and editorial interpretation? Could the old, familiar, disheartening, turf-protecting divide of scholarship and criticism be thus bridged? The Alexandrians had no trouble mixing textual commentary with exegesis. Why should not we, in our digital environment, now follow suit?

\section{Bibliography}

Andrews, Tara. 2016. "Freeing our Texts from their (Digital Tool) Chains". TEI 2016 Book of Abstracts. <http:/ / tei2016.acdh.oeaw.ac.at/sites/default/files / TEIconf2016_BookOfAbstracts.pdf> [Accessed 25 October 2016].

Bauman, Syd. 2011. "Interchange vs. Interoperability". Paper delivered at Balisage: The Markup Conference <http:/ / balisage.net/Proceedings/vol7/html/Bauman01/ BalisageVol7-Bauman01.html> [Accessed 25 October 2016].

Blouin, Francis X. Jr. and William G. Rosenberg. 2011. Processing the Past: Contesting Authorities in History and the Archives. Oxford: Oxford University Press. <https:/ /global.oup.com/academic/ product/processing-the-past-9780199740543?cc=us\&lang=en\&> [Accessed 12 June 2016].

Bode, Katherine and Roger Osborne. 2014. "Book History from the Archival Record". In Leslie Howsam, ed., The Cambridge Companion to the History of the Book. Cambridge: Cambridge University Press, pp. 219-36.

Bohnenkamp, Anne, Silke Henke and Fotis Jannidis, eds. 2016. FaustEdition. $<$ www.faustedition.net $>$ [Accessed 22 March 2016].

Bowers, Fredson. 1966. "Textual Criticism". In Oscar James Campbell and Edward G. Quinn, eds., A Shakespeare Encyclopaedia. London: Methuen, pp. 864-69.

1978. “Greg's Rationale of Copy-Text Revisited". Studies in Bibliography, 31, pp. 90-161.

Brüning, Gerrit, Katrin Henzel and Dietmar Pravida. 2013. “Multiple Encoding in Genetic Editions: The Case of Faust". Journal of the Text Encoding 
Initiative, 4 (March). <https://journals.openedition.org/jtei/697> [Accessed 27 October 2016].

Coats, Lauren and Gabrielle Dean. n.d. Modern Language Association

Commons Digital Pedagogy in the Humanities: Concepts, Models and Experiments.

$<$ https://digitalpedagogy.commons.mla.org/keywords/archive/> [Accessed 17 June 2016].

Connor, Francis X. 2015. "The Cambridge Edition of the Works of Ben Jonson Online". Review Article. Papers of the Bibliographical Society of America, 109(2), 247-63.

Cummings, James. 2013. “ODDly Pragmatic: Documenting Encoding Practices in Digital Humanities Projects". Paper presented at JADH 2013. $<$ https:/ / prezi.com/af2auinap-ug/jadh-2013-oddly-pragmaticdocumenting-encoding-practices-in-digital-humanities-projects/> [Accessed 27 October 2016].

Eggert, Paul. 2009. Securing the Past: Conservation in Art, Architecture and Literature. Cambridge: Cambridge University Press.

. 2012a. "Text, Work and Authorship in the Age of the Digital Humanities: Reconceiving the Philological Endeavour". Paper presented at воок:LOGIC 4, University of Western Australia, Perth, 29 June 2012.

—. 2012b. "The Hand of the Present". Textual Cultures, 7(2), pp. 3-19.

—. 2013. "What We Edit, and How We Edit; or, Why Not to Ring-fence the Text". Ecdotica, 10, pp. 50-63.

—. 2016. "The Reader-Oriented Scholarly Edition", Digital Studies in the Humanities, 31(4), pp. 797-810.

Eggert, Paul with Kym McCauley. 1995. "Critical and Scholarly Editing in Australia and New Zealand in the Last Twenty-five Years: An Essay on the Nomenclature of Editions and a Representative Listing", Bibliographical Society of Australia and New Zealand Bulletin, 19, 241-55.

Gabler, Hans Walter. 2010. "Theorizing the Digital Scholarly Edition", Literature Compass, 7.2, 43-56.

——. 2015. "Digital Challenges to Scholarly Editing: Networking a Digital Scholarly Edition". Paper presented at Key Ideas and Concepts of Digital Humanities conference, Darmstadt University, 26-28 October 2015.

— . 2016. "The Draft Manuscript as Material Foundation for Genetic Editing and Genetic Criticism". Variants, 12-13, pp. 135-45.

Holmes, Martin. 2015. “Whatever Happened to Interchange?" DH2015 Conference Abstracts. <http://dh2015.org/abstracts/> [Accessed 25 October 2016].

Huitfeldt, Claus. 2006. "Philosopy Case Study". In Lou Burnard, Katherine O'Brien O'Keeffe, and John Unsworth, eds., Electronic Textual Editing. New York: Modern Language Association of America, pp. 181-96. Preprint, n.d. $<$ http://www.tei-c.org/About/Archive_new/ETE/

Preview/huitfeldt.xml>. [Accessed 31 March 2016]. 
Ide, Nancy and C. M. Sperberg-McQueen. 1988. "Proposal for Funding for an Initiative to Formulate Guidelines for the Encoding and Interchange of Machine-Readable Texts Application for Funding for the TEI". <http:/ / www.tei-c.org/Vault/SC/scg02.html> [Accessed 25 October 2016].

Jannidis, Fotis. 2010. “Digital Editions in the Net: Perspectives for Scholarly Editing in a Digital World". In Jörgen Schäfer and Peter Gendolla, eds., Beyond the Screen: Transformations of Literary Structures, Interfaces and Genre. Bielefeld: Transcript Verlag, 2010, pp. 543-60.

Keleman, Erick. 2009. Textual Editing and Criticism: An Introduction. New York: Norton.

Manoff, Marlene. 2005. "Theories of the Archive from across the Disciplines", Portal: Libraries and the Academy, 4(1), pp. 9-25.

McGann, Jerome. 2014. A New Republic of Letters: Memory and Scholarship in the Age of Digital Reproduction. Cambridge, Mass.: Harvard University Press.

McLoughlin, Tim. 2008. "Bridging the Gap". Jahrbuch für Computerphilologie, 10. <http:/ / computerphilologie.tu-darmstadt.de/jg08/mclough.pdf>. [Accessed 12 June 2016].

Mueller, Martin. 2011. "Open Letter to the TEI". teiletter.pdf listed at <http:/ / ariadne.northwestern.edu/mmueller> [Accessed 25 October 2016].

Pierazzo, Elena. 2011. "A Rationale of Digital Documentary Editions", Literary and Linguistic Computing, 26(4), pp. 463-78.

—. 2015. Digital Scholarly Editing: Theories, Models and Methods. Farnham, Surrey: Ashgate.

Prenowitz, Eric. 1995. "Introduction: On the Intersections of Archives and History". In Eric Prenowitz, trans., Jacques Derrida, Archive Fever: A Freudian Impression. Chicago: University of Chicago Press.

Price, Kenneth M. 2009. "Edition, Project, Database, Archive, Thematic Research Collection: What's in a Name?", Digital Humanities Quarterly, 3(3). $<$ http://www.digitalhumanities.org/ dhq/vol/3/3/000053/000053.html> [Accessed 1 April 2016].

Robinson, Peter. 2013a. "Towards a Theory of Digital Editions". Variants, 10, pp. 105-31.

—. 2013b. "The Concept of the Work in the Digital Age", Ecdotica, 10, pp. $13-42$.

—. 2013c. "SDSE 2013: Why Digital Humanists Should Get Out of Textual Scholarship". <www.academia.edu/4124828> [Accessed 13 March 2016].

Robinson, Peter and Barbara Bordalejo. n.d. Canterbury Tales Project II <http:/ / www.textualcommunities.usask.ca/web/canterbury-tales> [Accessed 22 March 2016].

Sahle, Patrick. 2007. "Digitalis Archiv — Digitale Edition: Anmerkungen zur Begriffsklärung". In Michael Stolz, Lucas Marco Gisi and Jan Loop, eds., Literatur und Literaturwissenschaft auf dem Weg zu den neuen Medien: Eine 
Standortbestimmung. Zurich: Germanistik.ch.

2008- . A Catalog of Digital Scholarly Editions.

<http:/ / www.digitale-edition.de> [Accessed 19 March 2016].

—. 2010. "Zwischen Mediengebundenheit und Transmedialisierung:

Anmerkungen zum Verhältnis von Edition und Medien". editio 24, pp. 23-36.

—. 2016. "What Is a Scholarly Digital Edition". In Matthew James Driscoll and Elena Pierazzo, eds., Digital Scholarly Editing: Theories and Practices. Cambridge, UK: Open Book Publishers, pp. 19-39.

Scheirer, Walter, Christopher Forstall and Neil Coffee. 2016. "The Sense of a Connection: Automatic Tracing of Intertextuality by Meaning", Digital Scholarship in the Humanities, 31(1), 204-17.

Schmidt, Desmond. 2014. "Towards an Interoperable Digital Scholarly Edition", Journal of the Text Encoding Initiative, 7, DOI 10.4000/jtei.979 <http:/ /jtei.revues.org/979>. [Accessed 25 October 2016].

Shillingsburg, Peter. 1996. Scholarly Editing in the Computer Age. 3rd ed.: Ann Arbor: Michigan University Press.

2014. "Development Principles for Virtual Archives and Editions", Variants, 11, pp. 11-28.

Sperberg-McQueen, C. M. 1994. "Textual Criticism and the Text Encoding Initiative". <http://www.tei-c.org/Vault/XX/mla94.html> [Accessed 25 October 2016].

Tanselle, G. Thomas. 1978. "The Editing of Historical Documents", Studies in Bibliography, 31, pp. 1-56.

Text Encoding Initiative. 2007. TEI: P5 Guidelines. <http:/ / www.tei-c.org/Guidelines/P5/> [Accessed 7 August 2016].

Theimer, Kate. 2012. "Archives in Context and As Context", Journal of Digital Humanities, 1.2 (Spring), <http:/ /journalofdigitalhumanities.org/12/archives-in-context-and-as-context-by-kate-theimer/> [Accessed 17 June 2016].

Van Hulle, Dirk and Mark Nixon. 2015. "Editorial Principles and Practice". In van Hulle et al., eds., Samuel Beckett Digital Manuscript Project. <http://www.beckettarchive.org/2-editorial.jsp> [Accessed 1 April 2016].

Yale, Elizabeth. 2015. "The History of Archives: The State of the Discipline". Book History, 18, pp. 332-59.

Zeller, Hans. 1995. "Record and Interpretation: Analysis and Documentation as Goal and Method of Editing". In Hans Walter Gabler, George Bornstein and Gillian Borland Pierce, eds., Contemporary German Editorial Theory. Ann Arbor: University of Michigan Press, pp. 17-58. 